Ciência e Natura, Santa Maria, v. 37 n. 4 set-dez 2015, p. 34-54

Revista do Centro de Ciências Naturais e Exatas - UFSM

ISSN impressa: 0100-8307 ISSN on-line: 2179-460X

\title{
ASPECTOS MORFOLÓGICOS E FISIOLÓGICOS DA GERMINAÇÃO E MORFOMETRIADE FRUTOS E SEMENTES DE Swartzia recurva POEP. (FABACEAE)
}

\section{MORPHOLOGICAL ANDPHYSIOLOGICAL ASPECTS OF GERMINATION AND MORPHOMETRY OF FRUITS AND SEEDS OF Swartzia recurva POEP. (FABACEAE)}

\begin{abstract}
Margareth Aparecida dos Santos ${ }^{1}$, Lúcia Filgueiras Braga ${ }^{1}$, Rubens Marques Rondon Neto ${ }^{1}$, Adriana
\end{abstract} Matheus da Costa Sorato ${ }^{1}$

\author{
${ }^{1}$ Faculdade de Ciências Biológicas e Agrárias, Universidade do Estado de Mato Grosso - UNEMAT
}

\begin{abstract}
Resumo
Objetivou-se fornecer dados da morfometria de frutos e sementes, germinação e do desenvolvimento pós-seminal de Swartzia recurva. Foram avaliados: massa fresca, comprimento, largura e espessura dos frutos/sementes. Quanto à forma, coloração e textura do pericarpo e nas sementes observou-se: forma, coloração, textura e presença de projeções carnosas descreveu a. emergência, tipo de morfologia da plântula, hipocótilo e epicótilo, cotilédone e eofilos. O teste de germinação foi conduzido na luz e escuro contínuo, avaliando-se a porcentagem e índice de velocidade de germinação, tempo médio de germinação, frequência relativa, índice de sincronização, indice de germinação relativa à luz, comprimento de parte aérea e raiz, massa fresca e seca das plântulas. A maior variação ocorre na massa das sementes. A semente apresenta arilo desenvolvido, cor creme, hilo linear com posição mediana, circundado por uma linha marrom ferruginea distinguindo as sementes desta espécie, cujas medidas diferem de outras espécies do gênero. A presença de luz na temperatura de $30^{\circ} \mathrm{C}$ promove maior germinação de sementes indicando que essa espécie se comporta como fotoblástica positiva preferencial. A germinação é hipógea, a plântula é criptocotiledonar. A planta jovem apresenta caule lenhoso, eófilo, trifoliolados verde-violáceos no ápice, pecíolos e ráquis levemente alados e presença de estípulas e estipelas.
\end{abstract}

Palavras-chave: Muirajibóia amarela; germinação; características biométricas; fotoperíodo.

\begin{abstract}
Aimed to provide morphometric data of fruits and seeds, germination and post-seminal development of Swartzia recurva. Were evaluated: fresh weight, length, width and thickness of fruits / seeds. As for shape, color and texture pericarp and seeds observed shape, color, texture and presence of fleshy projections. The emergency was described, type of morphology of seedlings, hypocotyl and epicotyl, cotyledon and eophylls. The germination test was conducted in the light and continuous darkness, evaluating the percentage and speed of germination index, mean germination time, relative frequency, synchronization index, germination index on the light, shoot length and root mass fresh and dry seedling. The greatest variation occurs in the weight of the seeds. The seed has developed aryl, cream, linear hilum with a median position, surrounded by a rusty brown line distinguishing the seeds of this species, whose measures differ from other species of the genus. The presence of light at $30^{\circ} \mathrm{C}$ temperature promotes greater germination seeds indicating that this species behaves as a preferred positive photoblastic. Germination is hypogeal, the seedling is cryptocotylar. The young plant has woody stem, eophylls green-violet trifoliolate at the apex, slightly winged petioles and rachis and presence of stipules and stipels.
\end{abstract}

Keywords: Muirajibóia-amarela; germination; biometric characteristics; photoperiod. 


\section{1-INTRODUÇÃO}

O manejo, a conservação e a reconstituição de florestas tropicais dependem da compreensão da regeneração e outros processos ecológicos que, por sua vez, estão atrelados à realização de estudos que permitam a precisa identificação das espécies vegetais a partir de suas fases juvenis (OLIVEIRA, 1993). Cruz et al. (2001) afirmaram que as informações sobre as características da germinação de espécies florestais representam a base da silvicultura e do manejo sustentado, uma vez que os estudos morfológicos permitem a classificação das espécies existentes nos bancos de sementes do solo, contribuindo para a compreensão da regeneração natural para a sucessão em ecossistemas florestais.

O gênero Swartzia pertence à tribo Swartzieae, família Fabaceae (Papilionoideae), com espécies ocorrentes em sua maioria na América do Sul sendo a Amazônia seu centro de dispersão, espalhando-se ao longo da bacia do Rio Amazonas, desde sua nascente no Peru até o litoral brasileiro, atingindo o sul da Venezuela, Guiana e parte da Colômbia (SANCHES et al., 1999). Segundo Cowan (1967) 90\% destas espécies ocorrem no Brasil.

Swartzia recurva Poepp., conhecida como muirajibóia-amarela, é uma árvore de dossel ou sub-dossel que ocorre frequentemente em platôs ou campinas (RIBEIRO et al., 1999). É uma espécie florestal de ampla ocorrência na Amazônia, sendo muito utilizada na regeneração de áreas degradadas devido ao rápido desenvolvimento.

Considerando que a subfamília Papilionoideae é conhecida pelo valor econômico, com plantas que são fonte de alimento, madeira, utilizadas como medicinais, na produção de inseticidas, artesanato e decoração, estudos sobre as espécies da família, especialmente no gênero Swartzia são importantes para determinar $\mathrm{o}$ potencial de uso. Apesar de sua importância $S$. recurva é pouco estudada, não havendo referências sobre as características biométricas dos frutos e sementes, bem como informações sobre a germinação e desenvolvimento desta espécie.

Considerando o exposto, o trabalho teve como objetivo fornecer dados da morfometria de frutos e sementes, da germinação e do desenvolvimento pós-seminal de Swartzia recurva, ampliando o conhecimento sobre a espécie.

\section{2-MATERIAL E MÉTODOS}

Os frutos de Swartzia recurva foram colhidos manualmente em abril de 2014. Os frutos foram separados avaliando-se os inteiros e maduros, quanto às características de forma, coloração e textura do pericarpo. Em seguida foram abertos manualmente para observação da estrutura interna, sendo descritos a coloração e textura do epicarpo e endocarpo.

As medidas dos frutos $\mathrm{e}$ sementes foram realizadas com auxílio de paquímetro digital com precisão de $0,1 \mathrm{~mm}$ e a massa obtida com 
balança de precisão de 0,001 g. Foram utilizados 50 frutos sendo selecionados os sadios, inteiros e maduros, e obtidos massa fresca, medidas de comprimento, diâmetro e espessura. A biometria das sementes foi realizada com 250 unidades ao acaso determinando-se individualmente a massa fresca, comprimento, largura e espessura. A massa de 100 sementes foi determinada com a pesagem de duas amostras de 100sementes em balança de precisão.

Nas sementes retiradas dos frutos, extraiu-se o arilo, realizou-se assepsia superficial por 15 minutos em solução comercial de hipoclorito de sódio $2,5 \%$, diluído em água destilada na proporção 7:1 (v:v), lavadas em água destilada por 15 minutos $\mathrm{e}$ tratadas com solução fungicida de Ridomil (Metalaxyl) na proporção de $1 \mathrm{~g} \mathrm{\textrm {L } ^ { - 1 }}$ durante 15 minutos. Após a assepsia as sementes foram semeadas em papel germitest e permaneceram em BOD por 30 dias, quando foi realizado o transplante das plântulas para sacos de polietileno com 10x18 cm contendo uma mistura de terra de barranco e palha de café carbonizada na proporção $3: 1(\mathrm{v}: \mathrm{v})$, sendo as mudas mantidas em ambiente de laboratório sob iluminação com lâmpadas fluorescentes até 120 dias após emergência.

Foram realizadas observações diárias, sendo considerada para descrição das sementes a forma, coloração, textura e presença de projeções carnosas. Para a descrição do desenvolvimento pós-seminal, registrou-se o início da germinação, determinado pela emergência da raiz primária, e o desenvolvimento das plântulas e plantas jovens, até a formação do primeiro metáfilo. Foram descritos o tipo de morfologia inicial da plântula, o desenvolvimento da raiz, hipocótilo e epicótilo, o tipo e a morfologia do cotilédone e dos eofilos.

A terminologia empregada na descrição das plântulas baseou-se nos trabalhos de Duke $(1965,1969)$, Duke e Polhill(1981), Miquel (1987) e Ribeiro et al. (1999). Considerou-se plântula a fase transcorrida entre a emissão da raiz primária e a expansão do primeiro eófilo (ou primeiro par) e planta jovem as diversas formas apresentadas pelo indivíduo até a produção e expansão do primeiro metáfilo (OLIVEIRA, 1997). As ilustrações dos frutos, sementes e das fases de desenvolvimento das plântulas e indivíduos jovens foram elaborados manualmente a olho nu.

Foram realizadas as seguintes determinações para caracterizar o potencial físico e fisiológico das sementes: Grau de umidade determinado com 10 repetições com uma semente cada utilizando o método da estufa a $105 \pm 3^{\circ} \mathrm{C}$, durante 48 horas, segundo as Regras para Análise de Sementes (BRASIL, 2009). Germinação realizada com dez amostras de 10 sementes em BOD à temperatura de $25^{\circ} \mathrm{C}$ na presença (fotoperíodo de 12 horas) e ausência de luz, em papel germitest umedecido com três vezes a massa do papel, no interior de saco plástico transparente ou dois sacos de polietileno preto para a condição de escuro contínuo. A cada dois dias o substrato foi umidecido 
com $20 \mathrm{~mL}$ de água destilada por rolo de papel. As contagens diárias foram encerradas aos 30 dias, sendo considerada a emissão da raiz primária com $0,5 \mathrm{~cm}$ de comprimento, com cálculo de acordo com Labouriau e Valadares (1976). Índice de velocidade de germinação (IVG determinado em conjunto com o teste de germinação de acordo com Maguire (1962). Índice de Germinação Relativa à Luz (GRL), calculado no final do período de avaliação de acordo com Milberg et al. (2000), sendo GRL = \%GL/ \%GL + GE, onde: GL é germinação na luz e GE é a germinação no escuro.

Os dados da biometria descritiva foram submetidos às análises estatísticas para determinação da média, desvio padrão, coeficiente de variação, assimetria $(S)$, curtose $(K)$, valor máximo e mínimo utilizando o programa estatístico $R$ versão 2.15.2 ( $R$ CORE TEAM, 2012). Os valores de referência adotados para o coeficiente de assimetria foram: $S<0$, distribuição assimétrica à esquerda e $S>0$, distribuição assimétrica à direita. Para os coeficientes de curtose foram: $\mathrm{K}>3$, distribuição mais "afilada" que a normal (leptocúrtica) e $\mathrm{K}<3$, distribuição mais "achatada" que a normal (platicúrtica). Na avaliação de correlações foram utilizadas as medidas entre as variáveis avaliadas de 50 frutos e suas respectivas sementes, consideraram-se as seguintes classes de correlação: forte $(0,8 \leq \mathrm{p}<1)$, moderada $(0,5 \leq \mathrm{p}<0,8)$, fraca $(0,1 \leq \mathrm{p}<0,5)$ e ínfima $(0 \leq \mathrm{p} \leq$ $0,1)$ conforme Santos (2010). Para análises e construção de histogramas foi utilizado o programa estatístico $R$ versão 2.15.2 (R CORE TEAM, 2012).

Os resultados obtidos da germinação foram submetidos à análise de variância utilizando o programa ESTAT. As médias dos tratamentos foram comparadas pelo teste de Tukey a $5 \%$ de probabilidade, sendo as médias do índice de sincronização transformadas pela $\sqrt{x+0,5}$.

\section{3- RESULTADOS E DISCUSSÃO}

Na biometria dos frutos de $S$. recurva (Tabela 1 ) observa-se que as medidas são consistentes, pois apresentaram baixo coeficiente de variação (C.V.) e de desvio padrão. Os frutos apresentaram valores médios de $42,3 \mathrm{~mm}$ de comprimento, 41,1 $\mathrm{mm}$ de largura, 19,1 $\mathrm{mm}$ de espessura e $19,0 \mathrm{~g}$ de massa fresca. As sementes com médias de comprimento, largura, espessura e massa fresca respectivamente de $33,2 \mathrm{~mm}, 27,8 \mathrm{~mm}$, $14,7 \mathrm{~mm}$ e $8,90 \mathrm{~g}$, apresentaram maior variação quando comparadas com as medidas dos frutos, sendo a massa de sementes com maior C.V. (21,25\%). A massa de 100 sementes foi de881,69 g, enquanto a massa da semente variou entre 1,18 e 13,62 g correspondendo de $12,03 \%$ a $55,64 \%$ da massa mínima e máxima dos frutos, respectivamente.

As classes de frequência relativa de comprimento dos frutos $S$. recurva indicam que a maior parte dos frutos (55\%) apresenta comprimentos entre 40,0 a $44,9 \mathrm{~mm}, 22 \%$ com comprimentos nas classes entre 35,0a $39,9 \mathrm{~mm}$ e entre 45,0 e 49,9 . Apenas 
$2 \%$ da amostra de frutos apresentaram medidas de comprimento entre 55,0 a $60,0 \mathrm{~mm} \mathrm{Na}$ largura dos frutos observou-se que $70 \%$ dos frutos mensurados apresentaram medidas de 40,0 a $43,9 \mathrm{~mm}, 22 \%$ entre 38,0 a 39,9 $\mathrm{mme} \%$ dos frutos com largura entre 34,0 a $37,9 \mathrm{~mm}$ e entre 44,0 a 48,0 mm(Figura 1).

As medidas da espessura dos frutos apresentaram-se distribuídas nas classes com valores entre 15,0 e $22,0 \mathrm{~mm}$ e maior porcentagem $(67 \%)$ nas classes com medidas entre 18,0 e $21,0 \mathrm{~mm}$. Para a massa fresca dos frutos, $40 \%$ da amostra continha massa entre 18,00 a $19,99 \mathrm{~g}, 16 \%$ massa entre 14,00 a 17,99 g e $16 \%$ entre 20,00 a 23,99 g, sendo esta variável com maior coeficiente de variação $(16,03 \%)$ (Figura 1). O comprimento e a massa fresca de frutos apresentaram coeficientes de assimetria positivos, indicando que frutos com menor comprimento e menor massa predominam na amostra analisada. A largura e espessura dos frutos apresentaram coeficientes de assimetria negativos, o que representa predominância de frutos com maior espessura e largura (Tabela 1). Todas as variáveis biométricas, exceto $\mathrm{o}$ comprimento de fruto, apresentaram distribuição platicúrtica, conforme o coeficiente de curtose $(K<3)$ indicando que a distribuição de frequência das variáveis analisadas é mais achatada do que a curva normal, ou seja, apresenta maior amplitude dos dados, enquanto o comprimento apresentou distribuição leptocúrtica $(\mathrm{K}>3)$, sugerindo baixa amplitude nos resultados. O comprimento do fruto é dessa forma uma variável mais estável e segura para se considerar na escolha de tamanhos de frutos de acordo com a finalidade do estudo. A massa do fruto possui uma leve assimetria à esquerda, com comportamento platicúrtico próximo ao mesocúrtico, indicando que esta variável se aproxima da normalidade, e que provavelmente a assimetria à esquerda nos valores de massa deve estar relacionada à redução na umidade do fruto (Tabela 1).

Tabela 1: Valores de mínimo, máximo, média, desvio padrão (DP), coeficiente de variação $(\mathrm{CV})$, assimetria $(\mathrm{S})$ e curtose $(\mathrm{K})$ referentes à caracterização biométrica de frutos e sementes de Swartzia recurva.

\begin{tabular}{|c|c|c|c|c|c|c|c|c|}
\hline & Variáveis & Média & $\begin{array}{l}\text { Valor } \\
\text { mínimo }\end{array}$ & $\begin{array}{l}\text { Valor } \\
\text { máximo }\end{array}$ & $\mathrm{DP}$ & C.V.(\%) & $\mathrm{S}$ & K \\
\hline \multirow{4}{*}{ 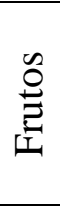 } & $\mathrm{m}$ & 42,35 & 36,02 & 57,68 & 0,55 & 9,21 & 1,13 & 3,46 \\
\hline & $\mathrm{L}(\mathrm{m}$ & 41,12 & 35,93 & 46,02 & 0,29 & 5,05 & $-0,20$ & 0,26 \\
\hline & $\mathrm{E}(\mathrm{mn}$ & 19,17 & 15,68 & 21,93 & 0,20 & 7,69 & $-0,36$ & $-0,33$ \\
\hline & $\mathrm{MF}(\mathrm{g})$ & 19,00 & 9,81 & 24,48 & 0,43 & 16,03 & 0,23 & 2,00 \\
\hline \multirow{5}{*}{ 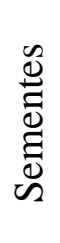 } & & 33,26 & 16,34 & 42,09 & 5,60 & 16,83 & $-1,07$ & 0,50 \\
\hline & $\mathrm{L}(\mathrm{m}$ & 27,82 & 13,07 & 35,07 & 3,45 & 12,42 & $-1,34$ & 2,97 \\
\hline & $\mathrm{E}(\mathrm{mm})$ & 14,70 & 7,62 & 37,97 & 2,68 & 18,26 & 0,90 & 2,26 \\
\hline & $\mathrm{MF}(\mathrm{g})$ & 8,90 & 1,18 & 13,62 & 1,90 & 21,25 & $-0,41$ & 1,06 \\
\hline & M100 (g) & 881,69 & & & 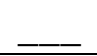 & & & $=-$ \\
\hline
\end{tabular}


$\mathrm{C}=$ comprimento, $\mathrm{E}=$ espessura, $\mathrm{L}=$ largura, $\mathrm{MF}=$ massa fresca e $\mathrm{M} 100=$ massa de 100 sementes.
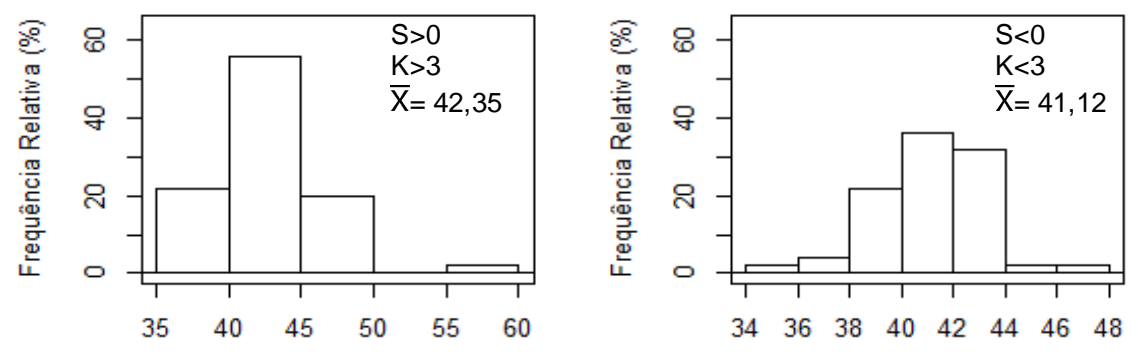

Comprimento do Fruto (mm)
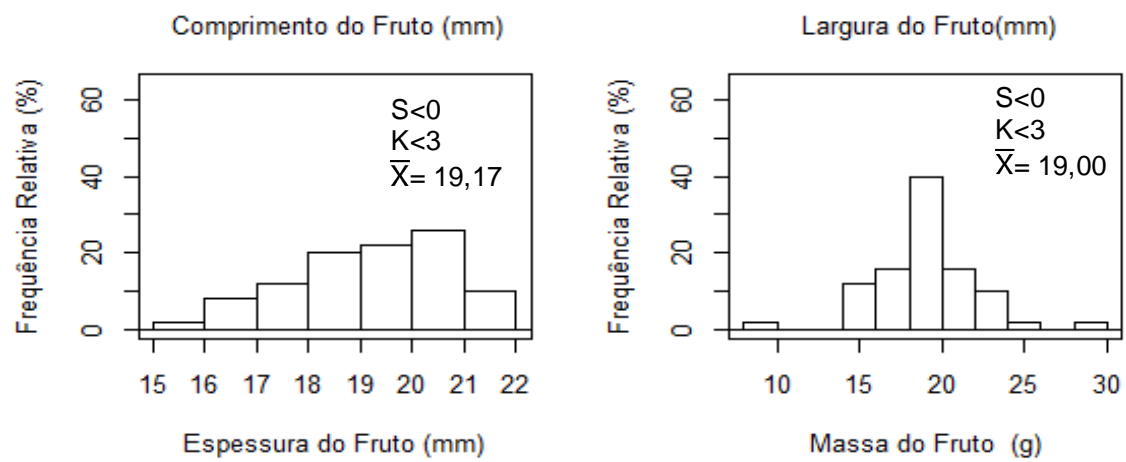

Figura 1: Frequências relativas do comprimento (mm), largura (mm), espessura (mm) e massa (g) de frutos de Swartzia recurva.

As classes de frequência relativa de comprimento das sementes indicam grande variação nos valores com $49 \%$ das sementes com 30,0 a 34,9 $\mathrm{mm}, 43 \%$ da amostra com 35,0 a 39,9 $\mathrm{mm}, 6 \%$ da amostra com 25,0 a 29,9 $\mathrm{mm}$ e apenas $2 \%$ das amostras apresentaram comprimento entre 15,0a 19,9 mm. Na variável largura a maior parte da amostra (69\%), apresentou distribuição concentrada na classe entre 25,0 a $29,9 \mathrm{~mm}, 19 \%$ entre 30,0 a $34,9 \mathrm{~mm}, 10 \%$ entre 20,0 a $24,9 \mathrm{~mm}$ e apenas $2 \%$ entre 10,0 a 15,0 mm (Figura 2).

As sementes apresentaram $84 \%$ das amostras com distribuição da espessura entre 14,0 a 15,9 mm (43\%) e entre 12,0 a 13,9 mm (41\%) (Figura 2). Os valores de massa fresca indicam que $71 \%$ das sementes apresentam massa nas classes entre 8,00 a $8,99 \mathrm{~g}$ (29\%), entre 10,00 a $10,99 \mathrm{~g}(24 \%)$ e entre 9,00 a $9,99 \mathrm{~g}(18 \%)$. O restante da amostra (29\%) apresentou massa variando de 5,00 a 7,99 g e de 11,00 a 12,99 g.As classes de medidas das sementes de $S$. recurva, mais representativas, são similares às descritas por Vieira e Scariot (2006) para sementes de $S$. multijuga Vogel que observaram comprimento de 30 $\mathrm{mm}$, largura de $20 \mathrm{~mm}$ e massa fresca de $8,97 \mathrm{~g}$.

As características biométricas das sementes apresentam coeficiente de assimetria positivo apenas para a espessura indicando que sementes com menor espessura predominaram na amostra. O comprimento, largura e massa das sementes apresentaram coeficientes de assimetria negativos, representando predominância de 
sementes com maiores medidas destas variáveis.

O coeficiente de curtose foi menor que três $(K<3)$ para todas as características e apresentam distribuição platicúrtica, demonstrando que a distribuição de frequência destas características é mais achatada que a curva normal, ou seja, apresenta maior amplitude de distribuição dos dados (Tabela 1).

As estimativas dos coeficientes de correlação de Pearson ( $p$ ) entre as características biométricas de frutos e sementes $S$. recurva encontram se na Tabela 2. As correlações foram todas positivas e variaram de 0,01 a 0,85 , e as significativas oscilaram de 0,28 a 0,85 . As correlações significativas entre as variáveis, comprimento e massa e entre largura e massa dos frutos, com valores respectivamente de 0,63 e 0,79, foram consideradas moderadas $(0,5 \leq \mathrm{p}<0,8)$, segundo critério de Santos (2010). Já a correlação entre o comprimento e largura $(0,38)$, entre largura e espessura $(0,28)$ e entre espessura e massa $(0,44)$ foram definidas como fracas $(0,1 \leq p<0,5)$. A correlação entre comprimento e espessura do fruto não foi significativa (Tabela 2).
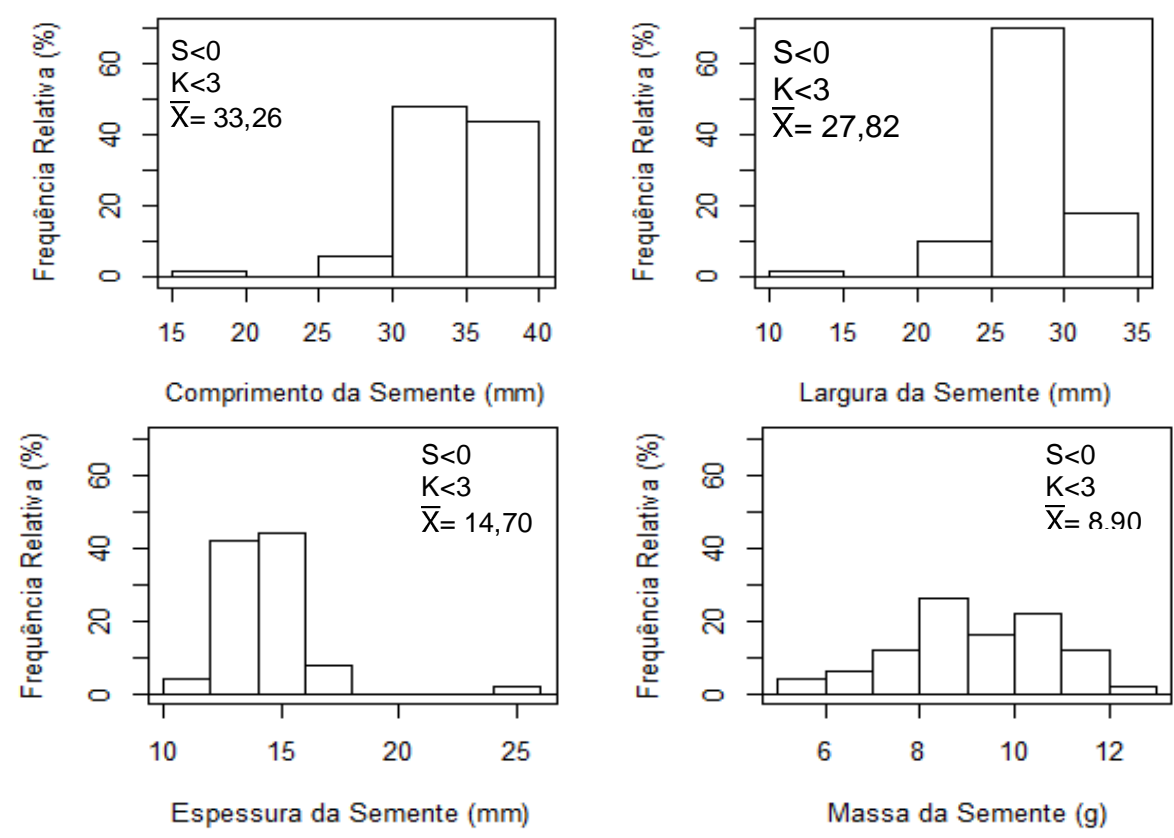

Figura 2: Frequências relativas do comprimento (mm), largura (mm), espessura (mm) e massa (g) de sementes de Swartzia recurva. 
Tabela 2: Matriz de coeficiente de correlações de Pearson das características do fruto e semente: comprimento $(\mathrm{mm})$, largura $(\mathrm{mm})$, espessura $(\mathrm{mm})$ e massa fresca $(\mathrm{g})$ de Swartzia recurva.

\begin{tabular}{|c|c|c|c|c|c|c|c|c|}
\hline & CF & LF & $\mathbf{E F}$ & MF & CS & LS & ES & MS \\
\hline CF & & $38^{* *}$ & $0,036^{\mathrm{NS}}$ & $0,637^{* *}$ & $0,37^{* *}$ & $0,33^{*}$ & $0,029^{\mathrm{NS}}$ & $0,40^{* *}$ \\
\hline $\mathbf{L F}$ & & 1 & $0,28^{*}$ & $0,79^{* *}$ & 0,28 & $0,57^{* *}$ & $0,08^{\mathrm{NS}}$ & $0,72^{* *}$ \\
\hline $\mathbf{E F}$ & - & - & 1 & $0,44^{* *}$ & $0,03^{\mathrm{NS}}$ & 0,0 & $0,65^{* *}$ & $0,47^{* *}$ \\
\hline MF & - & $\ldots$ & - & 1 & $0,36^{*}$ & 0,5 & $0.29^{*}$ & $0,85^{* *}$ \\
\hline CS & - & $\ldots$ & $\ldots$ & $\ldots$ & 1 & 0,6 & 0 & $0,35^{*}$ \\
\hline LS & $\ldots$ & $\ldots$ & $\ldots$ & $\ldots$ & _ & 1 & $0,01^{\mathrm{NS}}$ & $0,43^{* *}$ \\
\hline ES & $\ldots$ & - & $\ldots$ & - & $\ldots$ & $\ldots$ & 1 & $0,45^{* *}$ \\
\hline MS & - & $\ldots$ & $\ldots$ & $\ldots$ & $\ldots$ & $\ldots$ & $\ldots$ & 1 \\
\hline
\end{tabular}

CF: Comprimento do Fruto (mm); LF: Largura do Fruto (mm); EF: Espessura do Fruto (mm); MF: Massa do Fruto (g); CS: Comprimento da Semente (mm); LF: Largura da Semente (mm); ES: Espessura da Semente (mm); MS: Massa da Semente (g). Pelo teste t correlações acompanhadas de ${ }^{*},{ }^{* *}$ são significativas a $5 \%$ e a $1 \%$ respectivamente e NS caso seja não significativo.

Nas variáveis significativas avaliadas nas sementes, o maior coeficiente de correlação ocorreu entre o comprimento e largura $(0,65)$, considerada como moderada, enquanto as correlações de comprimento, largura e espessura com a massa das sementes $(0,35 ; 0,43$ e 0,45 respectivamente) classificadas como fracas (Tabela 2).

$\mathrm{Na}$ correlação entre variáveis dos frutos e sementes, o maior coeficiente ocorreu entre a massa do fruto e a massa da semente $(0,85)$, classificada como forte, segundo critério de Santos (2010) que considera como forte quando $0,8 \leq p<1$. As correlações entre largura do fruto com a largura e massa da semente, entre espessura do fruto e espessura da semente e entre massa do fruto e largura da semente foram moderadas $(0,5 \leq \mathrm{p}<0,8) \quad($ Tabela 2). $\mathrm{O}$ conhecimento das correlações existentes entre características dos frutos e sementes permite conhecer o comportamento de uma variável mediante a análise de outra. Neste caso com as medidas de largura e espessura e principalmente da massa fresca dos frutos pode-se estimar a massa, largura e espessura das sementes, o que significa que ao coletar frutos maiores há garantia de sementes maiores podendo-se também estimar a quantidade em gramas de sementes coletadas e a demanda de espaço para sua semeadura. Além disso, em algumas espécies, quanto maiores forem as sementes, maiores são as taxas de germinação e vigor de sementes (MARTINS et al., 2000).

As correlações não significativas foram aquelas oriundas da espessura do fruto com o comprimento e largura das sementes e entre a espessura das sementes com o comprimento e largura do fruto (Tabela 2).

As diferenças estatísticas nas características morfométricas avaliadas nos frutos e sementes de $S$. recurva (Tabela 1) indicam baixa influência do ambiente (através da 
temperatura e precipitação) nas variáveis dos frutos $(\mathrm{CV}<10 \%)$, enquanto para as sementes a influência pode ser considerada intermediária entre alto $(\mathrm{CV}$ de 20 a $30 \%$ ) e baixo, segundo classificação de Gomes (1990) o que significa que o ambiente apresentou maior ação sobre as características das sementes. No entanto, deve-se considerar que o componente genético tem forte influência no coeficiente de variação, especialmente em espécies alógamas cuja reprodução permite maior troca de genes elevando a variabilidade.

Nas espécies arbóreas tropicais existe grande variabilidade com relação ao tamanho dos frutos, número de sementes por fruto $\mathrm{e}$ tamanho das sementes (CRUZ e CARVALHO, 2003). Em Operculina macrocarpa L. Urban, Araujo et al. (2012), verificaram maior variação no comprimento dos frutos e no diâmetro das sementes, enquanto Andrade et al. (2010) estudando Hymenaea courbaril L. e De-Carvalho et al. (2005) avaliando Hymenaea stigonocarpa Mart. Hayne observaram alta variação na massa e número de sementes por fruto. Contudo, de acordo com Moraes e Alves (2002), o tamanho de diásporos de espécies arbóreas tropicais afeta a adaptação das árvores matrizes e o processo de regeneração da população, tendo-se evidenciado que diásporos de maior tamanho, provenientes de plântulas competitivamente superiores, apresentam maior germinação, crescimento e sobrevivência de plântulas.
O tamanho e a massa de frutos e sementes, bem como o número de sementes por fruto são característicos de cada espécie, existindo, porém, forte influência ambiental sobre os mesmos. Deste modo, a distinção e classificação das sementes por peso e tamanho pode ser uma maneira eficiente de melhorar a qualidade de lotes de sementes em relação à uniformidade de emergência e vigor das plântulas (PEDRON et al., 2004), garantindo maior valor dos lotes comercializados.

Em S. recurva aproximadamente $99 \%$ dos frutos amostrados possuíam uma semente por fruto, enquanto o restante desses, duas sementes, não se detectando frutos sem sementes, corroborando com dados biométricos de sementes de outras espécies de Swartzia, que indicam não haver variação com a presença de uma ou mais sementes por fruto, como descrito por Gonçalves et al. (2008) que observaram em Swartzia apetala Raddi, que o comprimento do fruto não variou com a presença de uma ou mais sementes.

Os maiores valores para comprimento do fruto e comprimento das sementes, obtidos no presente trabalho foram respectivamente de 40,0 a $44,9 \mathrm{~mm}$ e 30,0 a $34,9 \mathrm{~mm}$, maiores que os descritos por Gonçalves et al. (2008) para Swartzia apetala Raddi com $27 \mathrm{~mm}$ de comprimento dos frutos, e cujas sementes apresentaram $18 \mathrm{~mm}$ de comprimento. Em Swartzia acreana Cowan, coletadas no Acre, os frutos apresentaram 50 a $95 \mathrm{~mm}$ de 
comprimento e as sementes 40 e 30 $\mathrm{mm}$ respectivamente de comprimento e largura (COWAN, 1985), valores que superaram as medidas observadas para S. recurva. Para S. macrostachya Benth. var. riedelii Cowan os frutos são relativamente maiores $(76 \mathrm{~mm}$ de comprimento), mas as sementes em maior número por fruto $(2.7 \pm 0.4)$ apresentaram 28 e $20 \mathrm{~mm}$ de comprimento e largura, respectivamente (CLIFTONCARDOSO et al., 2008), portanto medidas de comprimento de frutos e sementes pode ser um critério utilizado para distinguir estas espécies de Swartzia a campo.
O fruto de $S$. recurva é um legume achatado de formato globoso irregular, inerme, com uma ou raramente duas sementes (Figura 3AC), apresentando superfície lisa e glabra, epicarpo de cor marrom brilhante quando maduro (Figura 3A), com abertura ao longo da sua circunferência, valvas não septadas internamente. $\mathrm{O}$ endocarpo é bege fosco, fino e estreitamente em contato com a(s) semente(s) (Figura 3B, C). O formato do fruto é similar ao descrito para S. acreana Cowan (COWAN, 1985), porém difere do fruto de $S$. apetala Raddi que é descrito como ovoide e apresenta arilo branco (GONÇALVES et al., 2008). 


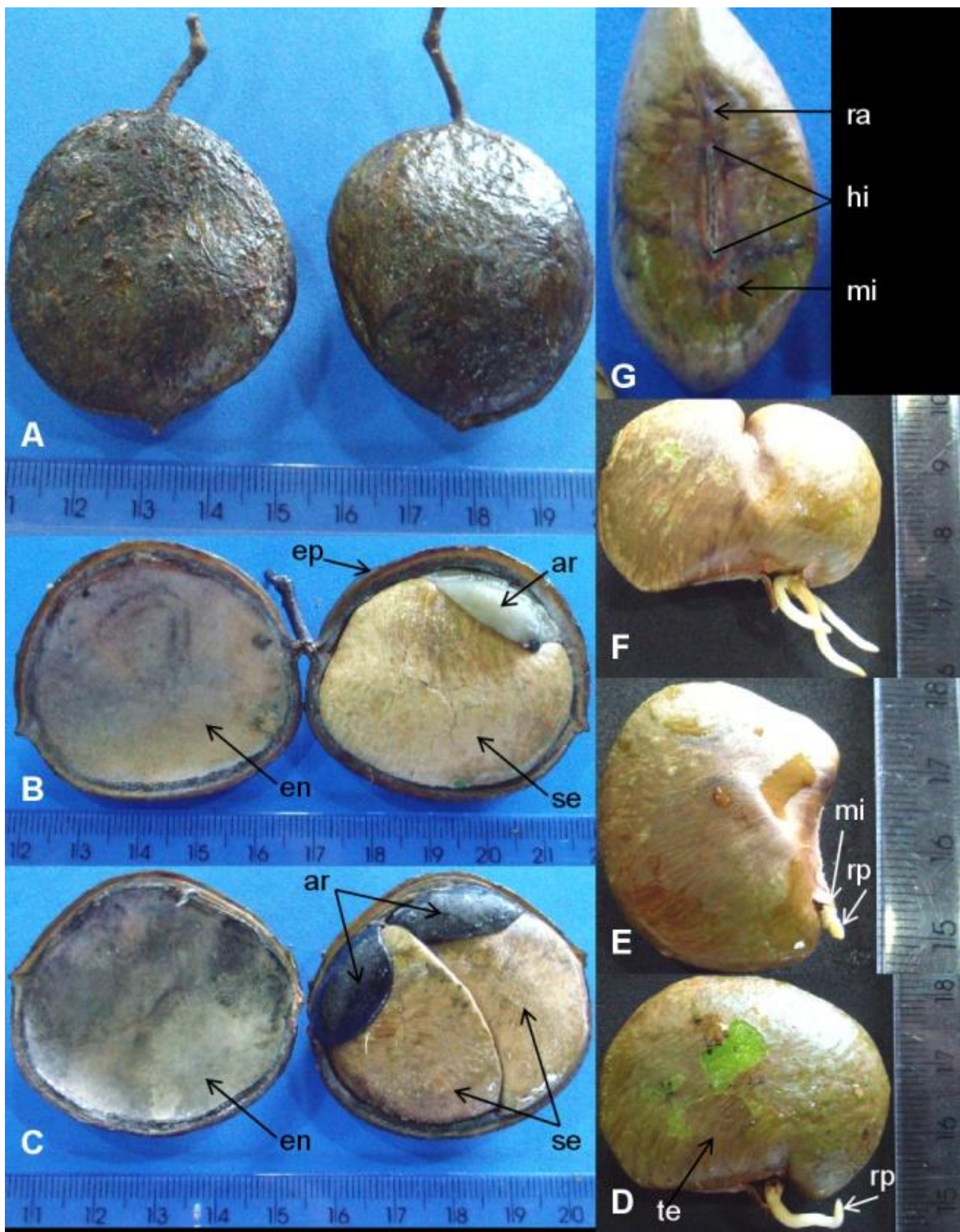

Figura 3. Aspecto do fruto maduro e sementes de Swartzia recurva. A) Fruto fechado, B-C) frutos abertos, D-F) vista lado frontal da semente, G) vista lado basal da semente. ar - arilo; en - endocarpo, ep - epicarpo; hi - hilo; mi - micrópila; ra - rafe; rp - raiz primária; se - semente; te - testa. Ilustração: L.F. Braga.

A semente é grande e carnosa, apresenta formato ligeiramente subgloboso em vista frontal (Figura
3D e 4B), sendo a vista lateral em formato de cunha e a basal (onde se encontra o hilo) achatada (Figura 3G 
e4A), com a testa fina, esfoliativa, de cor bege (quando a superfície está seca) a marrom claro (quando úmida) apresentando várias ranhuras deixando à mostra o cotilédone carnoso verde oliva (Figura 3D-E e 4B). Apresenta arilo muito desenvolvido, suculento, de cor creme (Figura 3B), tornando-se preto (com o passar do tempo de armazenamento dos frutos), posicionado lateralmente no sentido basal da semente (Figura 3B, C). No lado basal, a superfície da semente é ligeiramente côncava (Figura 3E, G), onde se encontra o hilo linear de posição mediana no sentido vertical da semente, circundado por uma linha de cor marrom ferrugínea, a rafe simples inconspícua (Figura 3G e 4A) e a micrópila localizada na base do hilo sobre uma pequena protuberância (Figura 3E, G e 4A).

Algumas sementes de $S$. recurva são poliembriônicas, apresentando até três embriões (dando origem a um sistema radicular ramificado) (Figura 3F), sendo que no total de 250 sementes, verificou-se a incidência de apenas duas sementes com 2 embriões e uma semente com 3 embriões. A poliembrionia também foi descrita para sementes de S. laevicarpa Amshoff (MOREIRA et al., 1995).

A germinação de $S$. recurva é hipógea e inicia aos três dias com a emissão da raiz primária fina, lisa, inflexa, de cor bege claro (Figura 3E e 4B) que se alonga cerca de $5 \mathrm{~cm}$ até os oito dias, ocasião em que é possível observar a abertura do tegumento na região da micrópila (Figura $3 \mathrm{D}, \mathrm{F}$ e 4C). Aos 14 dias, a raiz apresenta-se lenhosa com lenticelas por quase toda a sua extensão (Figura 4D), o epicótilo emerge do interior dos cotilédones foliáceos e carnosos, sendo cônico, verde-azulado, com superfície velutina brilhante.

$\mathrm{Na}$ plântula considerada criptocotiledonar, durante a fase de crescimento do epicótilo, entre os 14 e 60 dias, surgem de cinco a sete catafilos alternos (Figura 5A). A germinação hipógea criptocotiledonar também é característica de outras espécies de Swartzia, como para $S$. langsdorffii Raddi (OLIVEIRA et al., 2001), S. polyphylla DC. (SILVA et al., 1988) e S. apetala Raddi (GONÇALVES et al., 2008), nesta última porém a emissão da raiz principal e epicótilo é mais lenta (21 dias), sendo o epicótilo verde escuro, piloso e com 3-4 catáfilos alternos. Em S. laevicarpa Amshoffa germinação inicia aos 18 dias e atinge o clímax aos 25 dias (MOREIRA et al., 1995).

Aos 60 dias (Figura 5A) a plântula apresenta hipocótilo verde amarelado brilhante atingindo cerca de $15 \mathrm{~cm}$ ocorrendo catáfilos, que não dão origem a ramificações antes da expansão das primeiras folhas no ápice, que inicialmente apresentam o limbo dobrado junto à nervura central de coloração verde-violáceo, de textura fina e levemente transparente, ocorrendo a abertura do limbo após cerca de uma a duas semanas quando estas folhas exibem 3-5 cm de comprimento. O primeiro eófilo é trifoliolado, apresentando ráquis e pecíolo suavemente alados, com um par de estipelas encontradas na base. A raiz principal lenhosa, bege claro, apresenta ramificações oriundas da 
base que atingem comprimento e espessura semelhantes à primeira raiz formada, apresentando lenticelas próximas à base e inúmeras raízes secundárias e terciárias finas ao longo do seu comprimento.

A planta jovem, com 120 dias (Figura 5), ainda com os cotilédones, apresenta cerca de 40-50 cm de comprimento, raízes densamente ramificadas, lenhosas, sem nodulação e presença de lenticelas na base das raízes e caule. No caule a região da base é marrom esverdeado enquanto a parte superior é verde oliva. Após o primeiro eófilo a planta apresenta mais quatro ou cinco eófilos trifoliolados. A manutenção do cotilédone durante um longo período de tempo indica que esta espécie é provavelmente mais adaptada a ambientes sombreados. Esta característica também foi descrita para outras espécies do gênero, como $S$. apetala Raddi, cujos cotilédones desaparecem aos 90 dias e $S$. langsdorffii Raddi próximo de 180 dias (OLIVEIRA et al., 2001). De acordo com Swaine (1996) grupos funcionais de plântulas têm sido estabelecidos com base na principal função desempenhada pelos cotilédones. Cotilédones do tipo reserva são considerados uma adaptação à extensão do tempo de sobrevivência em ambientes sombreados. Também capazes de germinar a maior profundidade. No caso, como são sementes fotoblasticas positivas, talvez o sombreamento seja causa principal Em contraste, cotilédones fotossintéticos são considerados uma adaptação para explorar aumentos na disponibilidade luminosa através de áreas abertas da floresta.

A filotaxia é alterna e oposta, folhas glabras e brilhantes na face adaxial, reticuladas, com presença de estipelas (detalhe Figura 5B) e um par de estípulas com nervuras (Figura 6A). A folha apresenta forma estreitoelíptica, base obtusa e ápice agudo, pecíolo e ráquis alados (Figura 6A, B). Margem inteira, venação broquidódroma, sendo a terciária reticulada (Figura 6B). A forma estreito-elíptica da folha é similar à descrita para a espécie $S$. acreana Cowan (COWAN, 1985) e a presença de estípulas também foi verificada para S. langsdorffii Raddi (OLIVEIRA, 2001).

O grau de umidades das sementes de S. recurva foi 53,99\%, valor considerado dentro da faixa de 30 a $70 \%$, normalmente encontrado em sementes muito sensíveis à dessecação (MARCOS FILHO, 2005), indicando serem sementes recalcitrantes. Em sementes de $S$. macrostachya Benth. e $S$. simplex, também se verificou elevado teor de água $(42,0$ e $38,8 \%$, respectivamente) e sensibilidade à dessecação (CLIFTON-CARDOSO et al., 2008; DAWS et al., 2006). As sementes de $S$. recurva, germinando na presença de luz, iniciam a protrusão da raiz aos três dias após a semeadura, exibindo aos cinco dias comprimento $\geq 0,5 \mathrm{~cm}$, totalizando $96 \%$ de germinação aos 30 dias. 

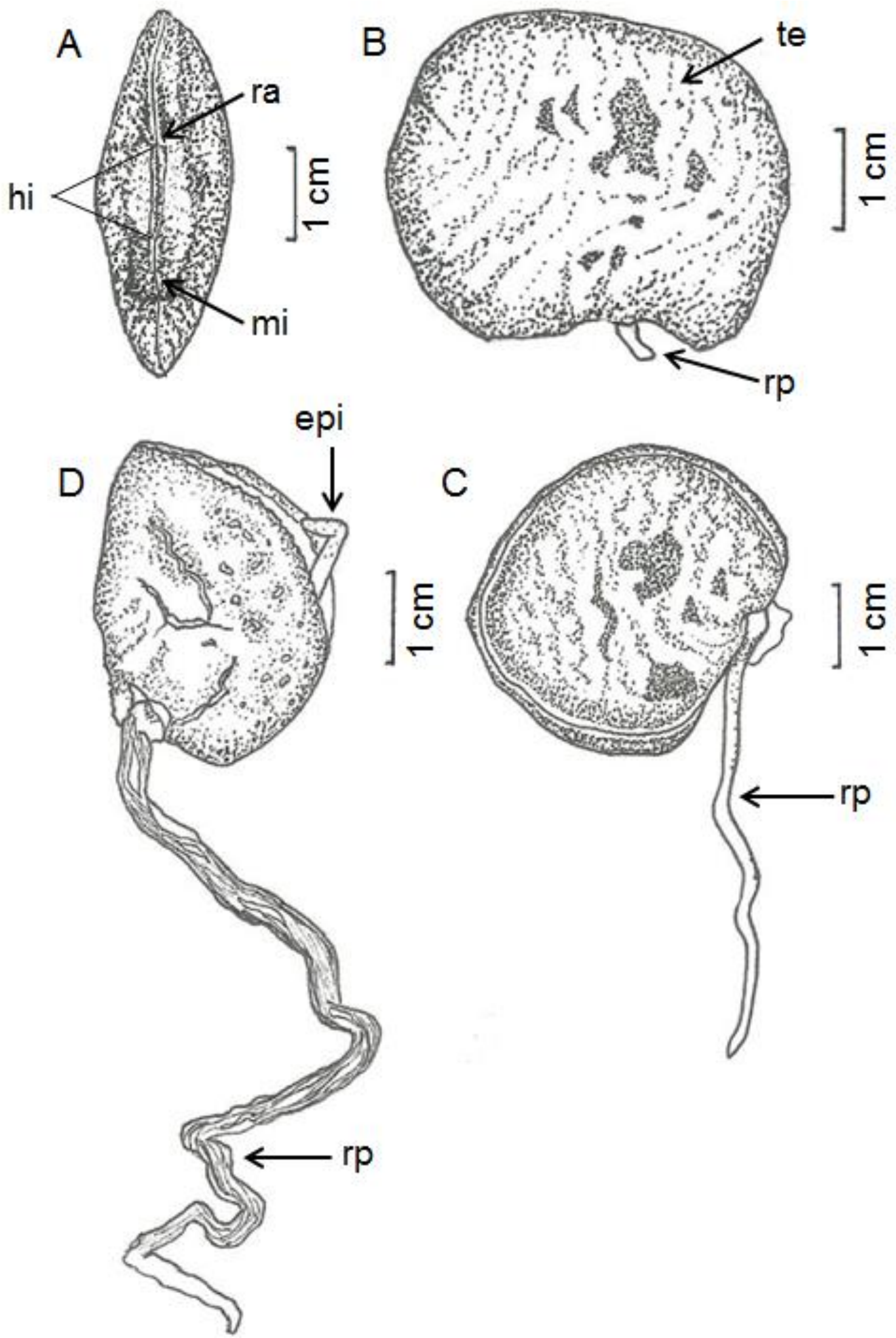

Figura 4. Aspectos morfológicos da semente e plântulas de Swartzia recurva. A. Semente em vista basal; B. Semente em vista frontal; C-D. Plântulas. epi - epicótilo; hi - hilo; mi - micrópila; ra - rafe; rp raiz primária; te - testa. Ilustração: L.F.Braga. 


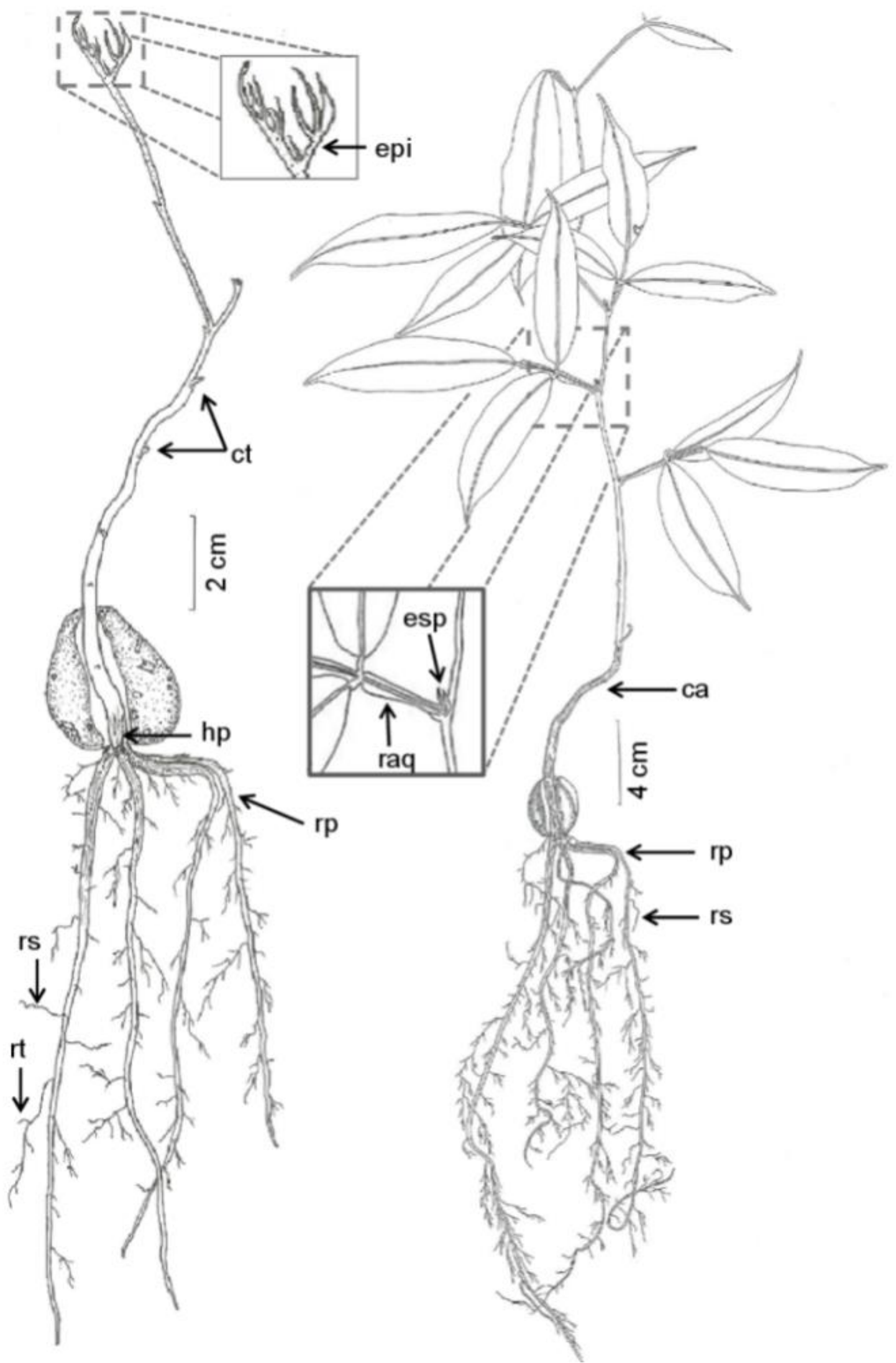

Figura 5: Aspectos morfológicos da plântula e planta jovem de Swartzia recurva. A. Plântula aos 60 dias; B. Planta jovem aos 120 dias. epi - epicótilo; esp - estipela; ca - caule; ct - catafilo; hi - hilo; $h p-$ hipocótilo; mi - micrópila; ra - rafe; $r p$ - raiz primária; raq-ráquis; $r s$ - raiz secundária; $r t$ - raiz terciária; $t e-$ testa. Ilustração: L.F.Braga. 
$\mathrm{Na}$ condição de escuro contínuo a germinação $\geq 0,5 \mathrm{~cm}$ inicia aos oito dias e a máxima germinação foi de $78 \%$, sendo estatisticamente maior a porcentagem e o IVG na presença de luz, condição mais adequada para condução do teste de germinação desta espécie (Figura 7A). Verificou-se que o Índice de Germinação Relativa à Luz (GRL) descrito por Milberg et al. (2000), com valores variando de zero(quando há germinação apenas no escuro) a um (quando ocorre germinação apenas na luz) que $S$. recurva apresentou valor de $0,55 \%$, o que confirma que a mesma têm maior germinação na presença de luz, mas é um fotoblastismo positivo relativo, pois também germina na ausência de luz,porém essa categoria não pode ser considerada como definitiva, uma vez que outros fatores podem alterar suas características fotoblásticas (BEWLEY e BLACK, 1994; TAKAKI, 2001). Este comportamento é ratificado pelo tempo médio de germinação que demonstra que as sementes germinando na luz levam em média 14 dias para germinar, enquanto no escuro o período aumenta para 21 dias (Figura 7B), demonstrando que a espécie se estabelece melhor e mais rapidamente em ambiente com disponibilidade de luz. Contudo o índice de sincronização da germinação indica que ocorreu maior sincronização do processo germinativo na ausência de luz (Figura 7B) o que pode estar relacionado com a concentração endógena do fitocromo na forma ativa induzindo uma resposta fisiológica sem a interferência de fator externo, como a iluminação.

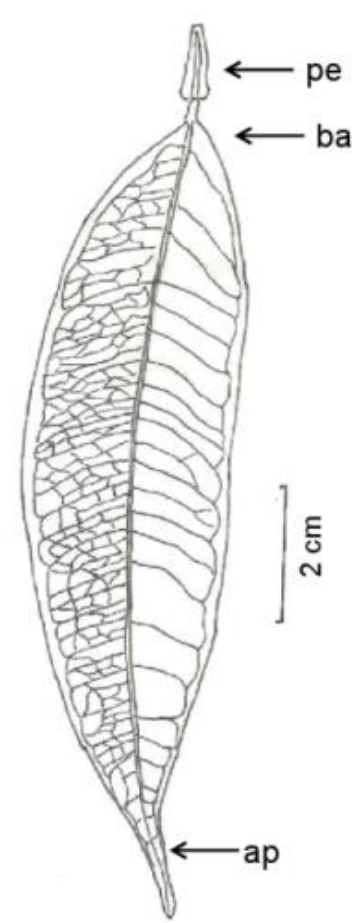

Figura 6: Aspectos morfológicos das folhas de Swartzia recurva. A- Folhas da ramificação basal de uma planta jovem; B- Folha do ápice caulinar da planta jovem. ap. ápice da folha; est - estípula; BA - base da folha; PE - pecíolo alado; raq - ráquis. Ilustração: L.F. BRAGA. 


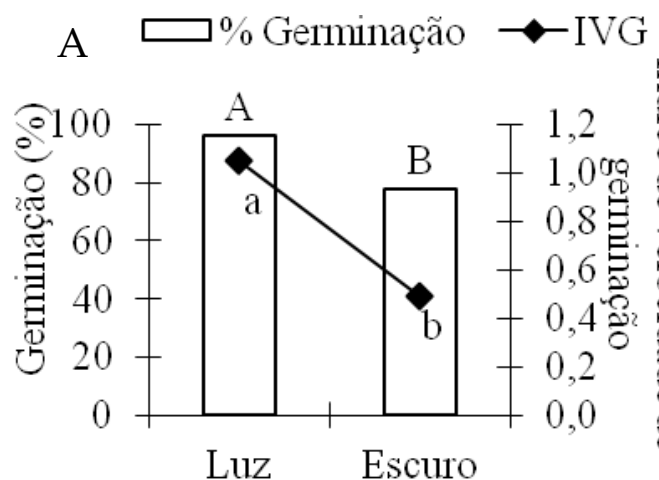

Fotoperíodo

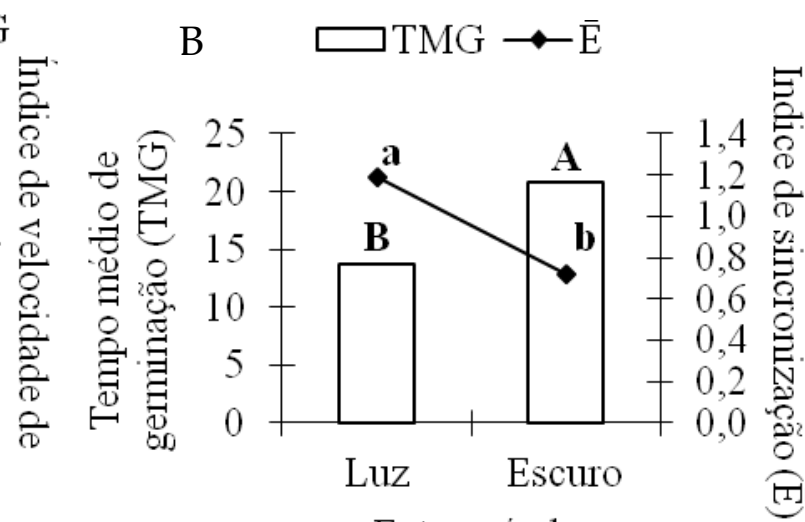

Fotoperíodo

Figura 7: Porcentagem e índice de velocidade de germinação (A), tempo médio de germinação e índice de sincronização (B) de Swartzia recurva sob duas condições de fotoperíodo.

A elevada viabilidade observada para $S$. recurva corrobora com resultados descritos para espécies do mesmo gênero. Para Swartzia madagascariensis Taub., a germinação ultrapassou 86\% (AMRI, 2010). Para S. apetala Raddi Gonçalves et al.(2008) relataram 93\% de germinação, enquanto para S. macrostachya Benth., Crifton-Cardoso et al. (2008) observaram $97 \%$ de germinação e para S. laevicarpa Amshoff $94 \%$ das sementes germinaram (MOREIRA et al., 1995). Para outras espécies de Swartzia os índices de germinação foram menores, como em S. multijuga Vogel que chegou a $63 \%$ em área de floresta, enquanto em área aberta (pasto) $76 \pm 10 \%$ das sementes sofreu dessecação ou predação (VIEIRA e SCARIOT, 2006). Para S. polyphylla DC. Atingiu 54\%em condições naturais (SILVA et al.,1988) e para $S$. langsdorffii obteve-se $48 \%$ em germinador e 36\% em estufa de sombrite (OLIVEIRA, 2001).

Segundo Thompson (1974), a germinação de muitas espécies é alterada de acordo com a amplitude da variação da presença ou ausência de luz. Em condições naturais, esta variação é determinada pelo período do dia e da noite. De acordo com Leite (1998), a luz é um fator determinante para que ocorra o processo de germinação, principalmente para espécies pioneiras. $\mathrm{Na}$ dinâmica de regeneração de florestas tropicais, existe grande número de sementes que germinam após aberturas de clareiras devido à queda de árvores ou formas de degradação do meio.

A germinação das sementes se distribui de forma diferente na condição de luz ou escuro contínuo, ao longo do tempo (Figura 8), indicando que na condição de luz os polígonos de frequência apresentam tendência unimodal apresentando acúmulo da germinação mais próximo ao eixo $x$ do gráfico, o que é evidenciando também pelo pico de germinação deslocado para a esquerda do gráfico reduzindo o TMG.

Com relação ao comprimento da parte aérea e raiz das plântulas verifica-se que na presença de luz os valores são estatisticamente superiores 
aos observados na condição de escuro contínuo (Figura 9 A), sendo que estas diferenças não afetaram a massa fresca e seca das plântulas que exibiram valores semelhantes na condição de luz e escuro (Figura 9 B).

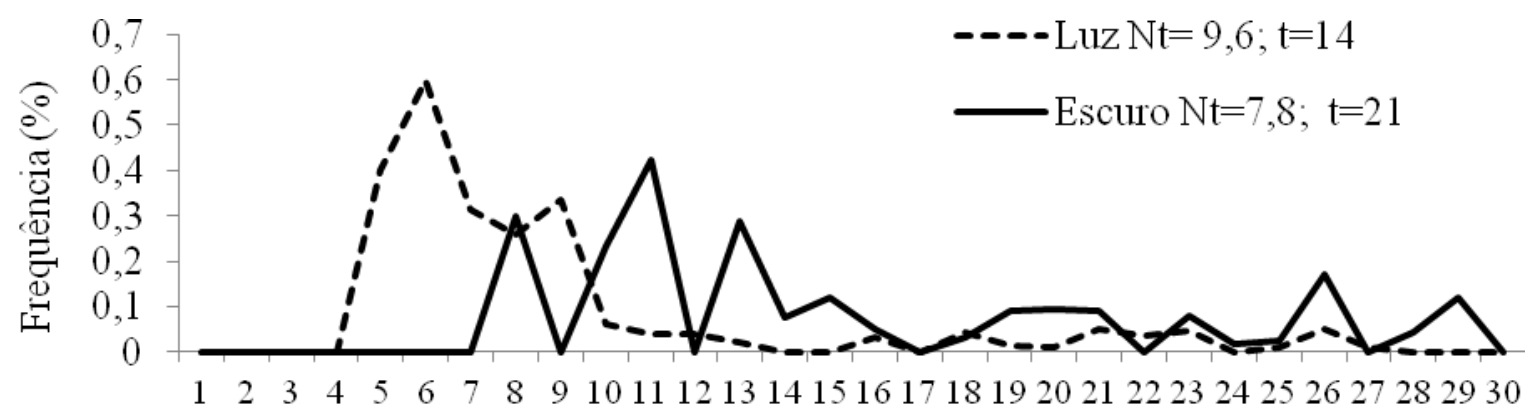

Tempo (dias)

Figura 8. Frequência relativa de germinação (\%) de Swartzia recurva sob duas condições de fotoperíodo.

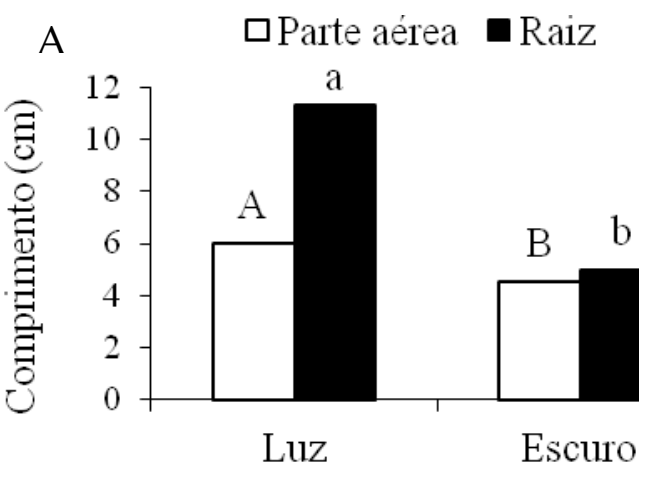

Fotoperíodo

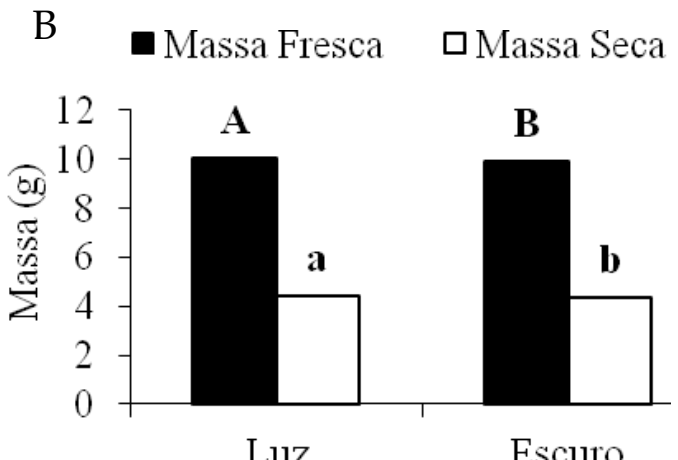

Fotoperíodo

Figura 9: Comprimento de parte aérea e raiz (A) e massa fresca e seca (B) de plântulas de Swartzia recurva, sob duas condições de fotoperíodo.

\section{4- CONCLUSÃO}

A maior variação nas características biométricas ocorre na massa das sementes, sendo que a partir da massa dos frutos pode-se estimar a massa das sementes devido a forte correlação entre estas características.

A semente apresenta arilo desenvolvido, de cor creme, hilo linear com posição mediana, circundado por uma linha marrom ferrugínea distinguindo as sementes desta espécie, cujas medidas diferem de outras espécies do gênero. A presença de luz na temperatura de $30^{\circ} \mathrm{C}$ promove maior germinação sementes indicando que essa espécie se comporta como fotoblástica positiva preferencial. A germinação é hipógea, a plântula é criptocotiledonar. A planta jovem apresenta caule lenhoso, eófilos trifoliolados verde-violáceos no ápice, pecíolos e ráquis levemente alados e presença de estípulas e estipelas. 


\section{AGRADECIMENTOS}

À FAPEMAT e a CAPES, pela concessão de bolsa à primeira autora.

\section{REFERÊNCIAS BIBLIOGRÁFICAS}

AMRI, E. The effect of pre-sowing seed treatments on germination of snake bean (Swartzia madagascariensis), a reported medicinal plant. American-Eurasian Journal Agricultural \& Environmental Sciences, India, v. 8, n 5, p. 525-529, mar. 2010.

ANDRADE, L. A.; et al. Aspectos biométricos de frutos e sementes, grau de umidade e superação de dormência de jatobá. Acta Scientiarum Agronomy, Maringá. v. 32, n. 2, p. 293-299, jun. 2010

ARAÚJO, P. C.; et al. Biometria de frutos e sementes de Operculina macrocarpa (L.) Urban ocorrente no semiárido Norte-riograndense. Scientia Plena, Sergipe, v 8, p. 01-05, abr. 2012.

BEWLEY, J. D.; BLACK, M. Seeds: Physiology o devopment end germination, Plenum Press, New York 445p., jun. 1994.

BRASIL. Ministério da Agricultura e Reforma Agrária. Regras para análise de Sementes. SNDA/DNDV/CLAV, Brasilia, 365p. 2009.

CARVALHO, J.E.U.; NAZARÉ, R.F.R.; OLIVEIRA, W.M. Características físicas e físico-químicas de um tipo de bacuri (Platonia insignis Mart.) com rendimento industrial superior. Revista Brasileira de Fruticultura, Jaboticabal, v. 25, n. 2, p. 326-328, jul. 2003.

CARVALHO, N.M.; NAKAGAWA, J. Sementes: Ciência, tecnologia e produção. 4 ed., Jaboticabal, Funep, 2000. 588 .

CLIFTON-CARDOSO, B. C. et al. Germination and seedling growth of Dimorphandra jorgei MF Silva and Swartzia macrostachya Benth. var. riedelii Cowan. New Forests, USA, v.35, p. 15-31, ago. 2008.

COUVILLON, G.A. Cercis canadensis L. seed size influences germination rate, seedling dry matter, and seedling leaf area. Hort science, New Orleans, v. 37, n.1, p. 206-207, dez. 2002.

COWAN, R.S. Flora Neotropica. Swartzia (Leguminosae- Caesalpinioideae, Swartzieae). Organization for Flora Neotropica, New York, v. 1, dez. 1967. 228p.

COWAN, R.S. Studies in tropical American leguminosae. Brittonia, New York, v. 37, p.291-304. set. 1985.

CRUZ, E.D.; CARVALHO, J.E.U. Biometria de frutos e sementes e germinação de curupixá (Micropholis cf. venulosa Mart. \& Eichler - Sapotaceae). Acta Amazônica, Manaus, v. 33, n. 3, p. 389-398, maio 2003.

CRUZ, E. D.; MARTINS, F. O.; CARVALHO, J. E. U. Biometria de frutos e sementes e germinação de jatobá-curuba (Hymenaea intermedia Ducke, Leguminosae-Caesalpinioideae). Revista Brasileira de Botânica, São Paulo, v. 24, p. 161-165. Jun. 2001.

DAWS, M. I.; GARWOOD, N. C.; PRITCHARD, $\mathrm{H}$. W. Prediction of desiccation sensitivity in seeds of woody species: a probabilistic model based on two seed traits and 104 species. Annals of Botany, Oxford, Reino Unido, v. 97, p. 667-674, dez. 2006. 
DE-CARVALHO, P. S.; MIRANDA, S. C.; SANTOS, M. L. Germinação e dados biométricos de Hymenae astigonocarpa Mart. Ex Hayne (Leguminosae Caesalpinoideae) - Jatobá-do-Cerrado. Revista Anhanqüera, Goiás, v. 6, p. 101116, Jan/dez. 2005.

DUKE, J. A. Keys for the identification of seedlings of some prominent woody species in eight forest types in Puerto Rico. Annals of the Missouri Botanical Garden, Washington, v. 52, p. 314-350, set. 1965.

DUKE, J. A. On tropical seedlings. I. Seeds, seedlings, systems and systematics.

Annals of the Missouri Botanical Garden, Washington, v. 56, p. 125-161, jun. 1969.

DUKE, J. A.; POLHILL, R. M. Seedlings of Leguminosae. In: POLHILL, R.M.; RAVEN, P.H. Eds. Advances in legume systematics. Royal Botanic Gardens, Londres, p. 941-949, fev. 1981.

GOMES, F. P. Curso de estatística experimental. 14 ed. Piracicaba, maio 1990. 468p.

GONÇALVEZ, I. P. et al.. Caracterização dos frutos, sementes de quatro espécies de leguminosa da restinga de Maricá, Rio de Janeiro. Rodriguésia, Rio de Janeiro, v. 59, p. 497-512, abr. 2008.

LABOURIAU, L. G.; VALADARES, M. E. $B$. On the germination of seeds Calotropisprocera (Ait) Ait.f. Anais da Academia Brasileira de Ciências, Rio de Jnaneiro, v. 48, 263-284, abr. 1976.

LABOURIAU, L. G.; PACHECO, A. On the frequency of isothermal germination in seeds of Dolichosbiflorus L. Plant and Cell Physiology, Tokyo, v.19, n.3,p. 507512, jul. 1978.
LEITE, I. T. A. Aspectos Fisiológicos da Germinação da Germinação de Sementes de Miconia cinnamomifolia (D.C.) Naud. - Melastomaceae. Rio Claro - SP, 1998, p.114. Tese (Doutorado em Ciências Biológicas, Área de Biologia Vegetal) Instituto de Biociências, Universidade Estadual Paulista. 1998.

MAGUIRE, J.D. Speed of germination-aid in selection and evaluation for seedling emergence and vigour. Crop Science, Madison, v. 2, p. 176-177, mar. 1962.

\section{MARCOS FILHO, J. Fisiologia de sementes de plantas cultivadas. Piracicaba. FEALQ, 495p. 2005.}

MARTINS, C.C.; NAKAGAWA, J.; BOVI, M. L. A. Influência do peso das sementes de palmito - vermelho (Euterpe espiritosantensis Fernandes- Palmae) na porcentagem e na velocidade de germinação. Revista Brasileira de Sementes, v. 22, n. 47-53, abr. 2000.

MILBERG, P.; ANDERSSON, L.; THOMPSON, K. Large seeded species are less dependent on light for germination than small seeded ones. Seed Science Research, Cambridge, v. 10, p. 99-104, abr. 2000.

MIQUEL, S. Morphologie fonctionelle de plantules d' especes forestières Du Gabon. Bulletindu Museum National d' Histoire Naturelle, Section B, Adansonia. Botanique Phytochimie, Paris, v. 9, p. 101-121, dez. 1987.

MORAES; P. L. R.; ALVES, M. C. Biometria de frutos e diásporos de Cryptocarya aschersoniana Mez e Cryptocarya moschata Ness (Lauraceae). Biota Neotropica, São Paulo, v. 2, n. 2, p. 1-19, abr. 2002. 
MOREIRA, F. W.; MOREIRA, F. M. de S.; SILVA, M. F. da. Germinação, crescimento inicial e nodulação em viveiro de saboarana (Swartzia laevicarpa Amshoff). Acta Amazônica, Manaus, v. 25, p. 149-160, dez. 1995.

NASSIF, S. M. L.; VIEIRA, I. G.; FERNADES, G. D. Germinação de sementes: fatores externos (ambientais) que influenciam a germinação. Informativo Sementes, IPEF, Piracicaba, abri,1998. Disponível em: $<$ http://www.ipef.br $>$. Acesso em: $10 \mathrm{de}$ outubro de 2014.

OLIVEIRA, D. M. T. Análise morfológica comparativa de frutos, sementes, plântulas e plantas jovens de 30 espécies arbóreas de Fabaceae ocorrentes no Estado de São Paulo. Rio Claro- SP, 1997, p.212. Tese (Doutorado em Ciências Biológicas, Área de Biologia Vegetal) Instituto de Biociências, Universidade Estadual Paulista. 1997.

OLIVEIRA, D. M. T.; BELTRATI, C. M. Morfologia comparada de plântulas e plantas jovens de leguminosas arbóreas nativas: espécies de Phaseoleae, Sophoreae, Swartzieae e Tephrosieae. Revista Brasileira de Botânica, Belo Horizonte, v. 24, n. 1, 85-97, jan. 2001.

OLIVEIRA, E. C. Morfologia de plântulas. In: AGUIAR, I. B. de; PIÑA-RODRIGUES, F. C. M.; FIGLIOLIA, M. B. (Ed.). Sementes florestais tropicais. Brasilia, ABRATES, p. 175-214, jul. 1993

PEDRON, F. A.; MENEZES, J. P.; MENEZES, N. L. Parâmetros biométricos de fruto, endocarpo e semente de butiazeiro. Ciência Rural, Santa Maria, v. 34, n. 2, p. 585-586, mar/abr.2004.
$\mathrm{R}$ CORE TEAM R. A language an environment for statistical computing: $R$ Foundation for statistical computing. 2012.

RIBEIRO, J. E. L. da S. et al.. Flora da Reserva Ducke: Guia de Identificação das plantas vasculares de uma floresta de terra firme na Amazônia Central. INPA, Manaus, 1999. 816p.

SANCHEZ, C. S. et al. BrachyrachisinaIsoflavona inédita de Swartzia (Leguminosae). Acta Amazônica, Manaus, v. 29, n3, p. 419-422, jan. 1999.

SANTOS, C. Estatística descritiva: Manual de auto aprendizagem. Lisboa, Sílabo, 2010. 264p.

SILVA, M. F. et al. Germinação natural de 10 espécies arbóreas da Amazônia. Acta Amazônica, Manaus, v. 18, p. 9-26, 1988.

SWAINE M. D. The Ecology of Tropical Forest tree Seedlings. Paris: UNESCO and Parthenon Publishing Group, v. 17, abr. 1996. 368p.

TAKAKI, M. New proposal of classification of seed based on forms of phytochrome instead of photoblastism. Revista Brasileira de Fisiologia Vegetal, Lavras, v.13, p. 104-108, mar. 2001.

THOMPSON, P.A. Effects of fluctuating temperature on germination. Journal of Experimental Botany, Reino Unido, v. 25, p. 164-175, abr. 1974.

VIEIRA, D. L. M.; SCARIOT, A. Effects of logging, liana tangles and pasture on seed fate of dry forest tree species in Central Brazil. Forest Ecology and Management, Amsterdam, v. 23, p. 197-205, jul. 2006. 